\title{
Thrombolytic treatment for myocardial infarction: an examination of practice in 39 United Kingdom hospitals
}

\author{
J S Birkhead, on behalf of the Myocardial Infarction Audit Group
}

\begin{abstract}
Objective-To examine use of thrombolytic drugs for myocardial infarction and use of contraindications to treatment in the United Kingdom.
\end{abstract}

Design-Observational study, based on a continuing audit.

Setting-39 hospitals in the United Kingdom.

Patients-30 029 patients admitted between November 1992 and June 1995 with suspected myocardial infarction.

Results-Of 13628 patients with a final diagnosis of definite myocardial infarction $10316(75 \cdot 7 \%)$ were considered eligible for thrombolytic treatment on the basis of typical cardiographic changes or new left bundle branch block. Of these, $8139(59.7 \%)$ were diagnosed at admission to hospital and $6991(85.9 \%)$ were administered thrombolytic drugs; $14.1 \%$ were considered too late for treatment or had a clinical contraindication. In 2177 patients (16\% of 13628$)$ thrombolytic treatment was given in the absence of contraindications and after the diagnosis of infarction had been confirmed by further electrocardiographic evidence. A further 591 (4.3\%) with a final diagnosis of definite infarction without typical cardiographic changes also received thrombolytic treatment as did 1018 patients without a final diagnosis of definite infarction. In total, 9459 of 13628 patients $(71 \cdot 6 \%)$ received thrombolytic treatment. The range of use of treatment between hospitals for a final diagnosis of infarction was $49 \cdot 1-85 \cdot 4 \%$. This variation reflected differences in the frequency with which a diagnosis of definite myocardial infarction was made at admission, and the subsequent use of clinical contraindications to thrombolytic treatment.

Conclusions-75.7\% of patients with a final diagnosis of definite myocardial infarction were eligible for thrombolytic treatment on the basis of cardiographic changes. Differences between hospitals in the frequency with which a diagnosis of infarction was made on admission, and differences in subsequent use of thrombolytic drugs, results in wide variation in treatment rates. Differences in use of thrombolytic treatment mainly reflect different thresholds for the use of clinical contraindications relating to haemorrhagic risk.
(Heart 1997;78:28-33)

Keywords: thrombolytic treatment; myocardial infarction; audit

Early and accurate recognition of the electrocardiographic changes of myocardial infarction is a prerequisite for the effective use of thrombolytic treatment. It is accepted that benefit extends to patients who show typical ST segment elevation or new left bundle branch block on the ECG, changes that are associated with thrombotic occlusion of a major epicardial artery. ${ }^{1-3}$ Benefit in infarction where there are not typical ST segment changes is not proven.

In theory the ideal figure for the use of thrombolytic treatment is the sum of patients eligible on ECG criteria minus those who have clear contraindications to treatment, either because of a perceived bleeding risk or because the delay after onset of symptoms is excessive. In practice this figure is not easily determined because neither cardiographic appearances nor contraindications are categorical variables and are subject to individual interpretation. In three recent large studies having similar enrolment criteria the proportion of patients with ECG ST segment elevation and who were thus eligible for thrombolytic treatment differed widely. In ISIS-2 $66 \%$ of patients had ST elevation, in ISIS-3 $75.9 \%$, and in ISIS-4 79\%.4-6

The contraindications to the use of thrombolytic treatment that reflect bleeding risk evolved over time as experience of this treatment increased. They may have become less stringent; in the GISSI-1 study (1984-85) $13.1 \%$ were considered to have a relative or absolute contraindication to thrombolysis ${ }^{1}$ while in GISSI-2 (1988-89) $10 \cdot 1 \%$ had clinical contraindications. ${ }^{7}$ In practice the use of thrombolytic treatment is determined by the attitudes of junior staff to borderline ECG appearances, and their perception of haemorrhagic risk particularly when using relative clinical contraindications. This, in turn, will depend on local training and supervision of junior staff by cardiologists.

Information on the number of patients admitted to hospital in the United Kingdom with infarction who have thrombolytic treatment is limited, and no longer up to date. In a study in the Trent region using pharmacy data and regional statistical returns, $35-50 \%$ of patients admitted to hospital with infarction of Cardiology, No Northampton NN1 BD United Kingdom.

Accepted for publication 22 April 1997 


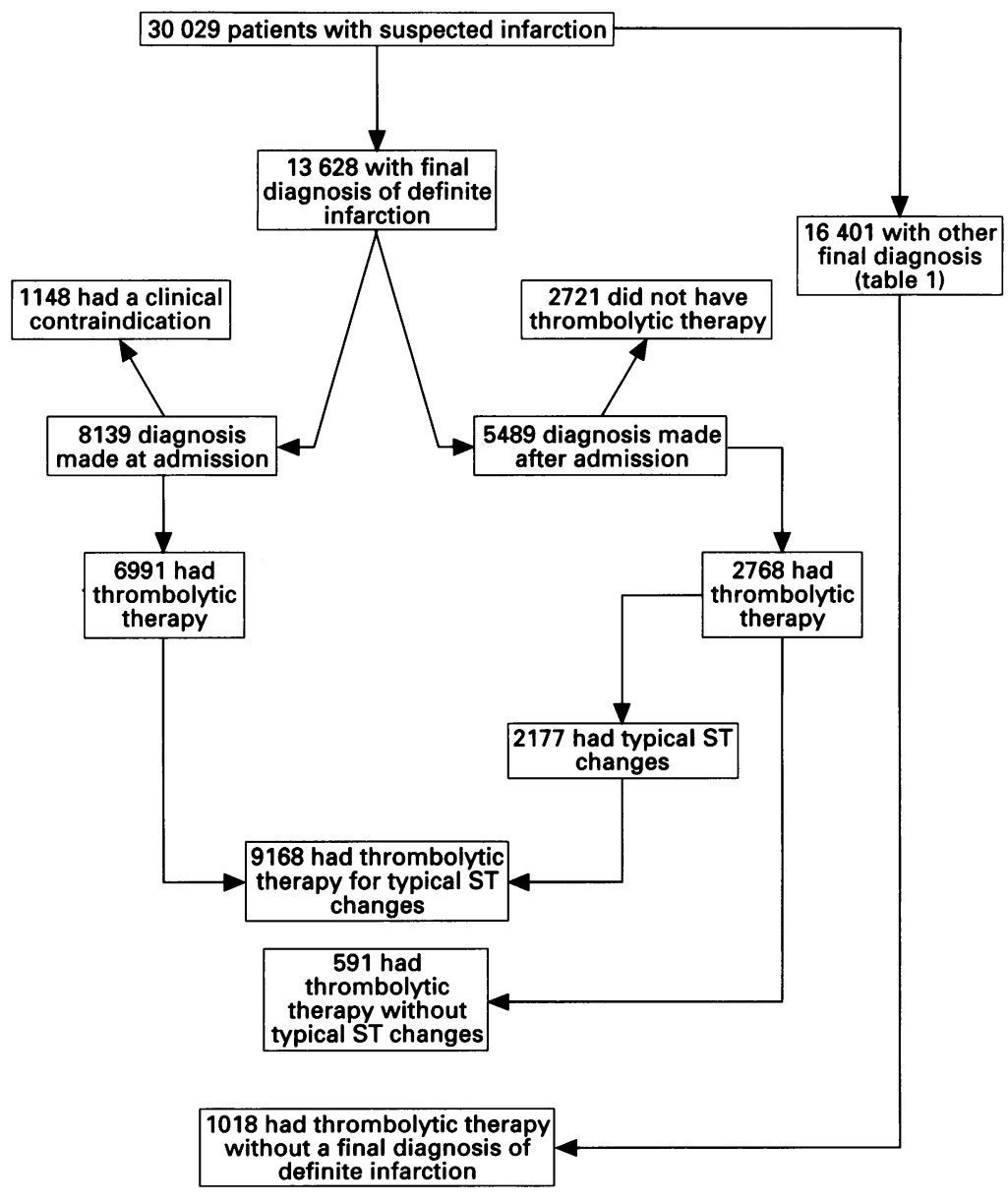

Treatment outcomes in 30029 patients with suspected myocardial infarction.

had thrombolytic treatment in $1991-92 .{ }^{8}$ In an earlier study (1990-91) 58\% of patients in six district general hospitals received thrombolytic treatment for a final diagnosis of infarction. ${ }^{9}$ In the United States lower figures have been recorded from the National Registry of Myocardial Infarction (35.1\%), ${ }^{10}$ and from academic hospitals $(29 \%) .{ }^{11}$ In a recent study from New Zealand $43.5 \%$ of patients with a final diagnosis of infarction received thrombolytic treatment. ${ }^{12}$

The present study examined the use of thrombolytic treatment in patients admitted with suspected myocardial infarction to cardiac care units in 39 hospitals in the United Kingdom between November 1992 and July 1995. The use of thrombolytic treatment, contraindications to treatment, and the factors that influenced the use of thrombolytic treatment were examined.

\section{Patients and methods}

In November 1992 a confidential collaborative audit of the timing and provision of thrombolytic treatment was established, and continues in more than 60 hospitals in the UK. The data in this study were collected between November 1992 and July 1995 from 39 hospitals that were among the earliest to enter the audit, and each contributed between 97 and 836 patients with a final diagnosis of myocardial infarction.
The diagnostic criteria used at admission were:

Definite infarction-A single episode of chest pain with the following ECG changes: ST elevation $\geqslant 1 \mathrm{~mm}$ in two limb leads, and/or ST elevation $\geqslant 2 \mathrm{~mm}$ in two contiguous chest leads, and/or new pathological $Q$ waves. For the final diagnosis cardiac enzymes had to be greater than twice the upper limit of normal.

Probable infarction - A single episode of chest pain with an abnormal but non-diagnostic cardiograph, and an enzyme release of less than twice the upper limit of normal.

Unstable angina-The development of spontaneous episodes of ischaemic pain or an increase in the frequency of ischaemic pain arising at rest or on minimal exertion. The cardiograph could be normal or abnormal and appearances could fluctuate but were not diagnostic of infarction.

Ischaemic heart disease-A single episode of chest pain, thought to be cardiac in origin, in a patient with a previous history of ischaemic heart disease.

Chest pain of uncertain cause-A single episode of chest pain, thought to be cardiac in origin, in a patient without a previous history of ischaemic heart disease.

A preprogrammed Psion organiser (Series II) was used for data collection. Data were collected prospectively during the course of the admission. It was not possible to identify an individual patient once the data had been entered. Data analysis was then performed centrally.

All treatment decisions were based on local protocols and the decision to use thrombolytic treatment was that of the junior staff of the collaborating hospitals.

\section{DATA ANALYSIS}

Proportions and their differences are expressed as percentages followed by $99 \%$ confidence intervals (CI) for the difference.

\section{Results}

There were 30029 patients admitted with symptoms suggestive of myocardial infarction of whom $13628(45.4 \%)$ had a final diagnosis of definite infarction (fig). Of 8481 patients who received an admission diagnosis of definite infarction, $8139(96.7 \%)$ had a final diagnosis of myocardial infarction and of these $6991(85.9 \%)$ received thrombolytic treatment (table 1). The majority of patients (8139 of $13628,59.7 \%$ ) with a final diagnosis of definite infarction was diagnosed at admission. In the remaining 5489 patients $(40.3 \%)$ the diagnosis was confirmed after admission. Patients in this group had admission diagnoses of probable infarction, unstable angina, ischaemic heart disease or chest pain of uncertain cause (table 1). Of patients with a delayed diagnosis of definite infarction $2768(50 \cdot 4 \%)$ received thrombolytic treatment. The cardiographic appearances of this group of patients are shown in table 2. Overall 9759 of 13628 patients $(71.6 \%)$ with a final diagnosis of definite infarction received thrombolytic treatment. 
Table 1 Admission and discharge diagnoses for 30029 patients admitted with suspected myocardial infarction

\begin{tabular}{|c|c|c|c|c|c|c|c|}
\hline \multirow[b]{2}{*}{$\begin{array}{l}\text { Admission } \\
\text { diagnosis }\end{array}$} & \multicolumn{7}{|c|}{ Final diagnosis } \\
\hline & $\begin{array}{l}\text { Definite } \\
\text { infarction }\end{array}$ & $\begin{array}{l}\text { Probable } \\
\text { infarction }\end{array}$ & $\begin{array}{l}\text { Unstable } \\
\text { angina }\end{array}$ & $\begin{array}{l}\text { Ischaemic } \\
\text { heart } \\
\text { disease }\end{array}$ & $\begin{array}{l}\text { Chest pain } \\
\text { of uncertain } \\
\text { cause }\end{array}$ & Other & Total \\
\hline $\begin{array}{l}\text { Definite infarction } \\
\text { Number having thrombolytic treatment }\end{array}$ & 8139 & $\begin{array}{r}113 \\
96\end{array}$ & 81 & 22 & $\begin{array}{r}12 \\
9\end{array}$ & $\begin{array}{l}47 \\
32\end{array}$ & 8414 \\
\hline $\begin{array}{l}\text { Probable infarction } \\
\text { Number having thrombolytic treatment }\end{array}$ & $\begin{array}{c}(85 \cdot 9 \%) \\
3135 \\
2015 \\
(64 \cdot 3 \%)\end{array}$ & $\begin{array}{l}(85 \%) \\
678 \\
262 \\
(38.6 \%)\end{array}$ & $\begin{array}{l}(84 \cdot 4 \%) \\
781 \\
172 \\
(22 \%)\end{array}$ & $\begin{array}{l}(68 \cdot 2 \%) \\
265 \\
49 \\
(18 \cdot 5 \%)\end{array}$ & $\begin{array}{l}(75 \%) \\
237 \\
55 \\
(23 \cdot 2 \%)\end{array}$ & $\begin{array}{l}(68 \cdot 1 \%) \\
374 \\
51 \\
(13 \cdot 6 \%)\end{array}$ & $\begin{array}{c}(85 \cdot 7 \%) \\
5470 \\
2604 \\
(47 \cdot 6 \%)\end{array}$ \\
\hline $\begin{array}{l}\text { Unstable angina } \\
\text { Number having thrombolytic treatment }\end{array}$ & $\begin{array}{c}1266 \\
355 \\
(28 \%)\end{array}$ & $\begin{array}{c}249 \\
41 \\
(16 \cdot 5 \%)\end{array}$ & $\begin{array}{c}5805 \\
45 \\
(0 \cdot 8 \%)\end{array}$ & $\begin{array}{c}428 \\
7 \\
(1 \cdot 6 \%)\end{array}$ & $\begin{array}{c}431 \\
2 \\
(0.5 \%)\end{array}$ & $\begin{array}{c}289 \\
2 \\
(0 \cdot 7 \%)\end{array}$ & $\begin{array}{r}8468 \\
452 \\
(5 \cdot 3 \%)\end{array}$ \\
\hline Ischaemic heart disease & 263 & 62 & 346 & 1135 & 172 & 176 & 2154 \\
\hline Number having thrombolytic treatment & $\begin{array}{c}47 \\
(17 \cdot 8 \%)\end{array}$ & $\begin{array}{c}5 \\
(8 \cdot 1 \%)\end{array}$ & $\begin{array}{c}5 \\
(1 \cdot 3 \%)\end{array}$ & $\begin{array}{c}3 \\
(0 \cdot 3 \%)\end{array}$ & 0 & $\begin{array}{c}1 \\
(0 \cdot 5 \%)\end{array}$ & $\begin{array}{r}61 \\
(2 \cdot 8 \%)\end{array}$ \\
\hline $\begin{array}{l}\text { Chest pain of uncertain cause } \\
\text { Number having thrombolytic treatment }\end{array}$ & $\begin{array}{c}825 \\
351 \\
(42 \cdot 5 \%)\end{array}$ & $\begin{array}{c}192 \\
41 \\
(21 \cdot 4 \%)\end{array}$ & $\begin{array}{c}834 \\
17 \\
(2 \%)\end{array}$ & $\begin{array}{c}344 \\
5 \\
(1 \cdot 5 \%)\end{array}$ & $\begin{array}{c}2239 \\
21 \\
(0.9 \%)\end{array}$ & $\begin{array}{c}1089 \\
14 \\
(1 \cdot 3 \%)\end{array}$ & $\begin{array}{r}5523 \\
449 \\
(8 \cdot 1 \%)\end{array}$ \\
\hline Total & $\begin{array}{c}13628 \\
9759 \\
(71 \cdot 6 \%)\end{array}$ & $\begin{array}{c}1294 \\
445 \\
(34 \cdot 4 \%)\end{array}$ & $\begin{array}{c}7847 \\
307 \\
(3.9 \%)\end{array}$ & $\begin{array}{c}2194 \\
79 \\
(3.6 \%)\end{array}$ & $\begin{array}{c}3091 \\
87 \\
(0.9 \%)\end{array}$ & $\begin{array}{c}1975 \\
100 \\
(0.9 \%)\end{array}$ & $\begin{array}{l}30029 \\
10777\end{array}$ \\
\hline
\end{tabular}

Table 2 Cardiographic appearances in patients having thrombolytic therapy for a delayed diagnosis of infarction

\begin{tabular}{lcc}
\hline ECG & Number & $\begin{array}{l}\text { Percentage } \\
\text { of all } \\
\text { infarctions } \\
(n=13628)\end{array}$ \\
\hline Typical appearances & 2017 & $14 \cdot 8 \%$ \\
Left bundle branch block & 160 & $1 \cdot 2 \%$ \\
Non-Q wave infarction & 92 & $0 \cdot 7 \%$ \\
Extensive ST depression & 174 & $1 \cdot 3 \%$ \\
Other ischaemic ECG & 250 & $1 \cdot 8 \%$ \\
Normal cardiograph & 75 & $0 \cdot 5 \%$ \\
Total & 2768 & $20 \cdot 3 \%$ \\
\hline
\end{tabular}

Of 10777 patients receiving thrombolytic treatment $1018(9.4 \%)$ did not have a final diagnosis of definite infarction. The final diagnosis in these patients was probable infarction in $445(4 \cdot 1 \%)$, unstable angina in $307(2 \cdot 8 \%)$, chest pain in patients with a previous history of ischaemic heart disease in $79(0.7 \%)$, chest pain of uncertain cause in $87(0.8 \%)$, and in 100 patients $(0.9 \%)$ there was another confirmed diagnosis, such as pericarditis.

\section{CONTRAINDICATIONS TO THROMBOLYTIC TREATMENT}

The contraindications specified for patients who did not receive thrombolytic treatment are listed in table 3

Table 3 Use of contraindications to thrombolytic treatment

\begin{tabular}{lccrr}
\hline & \multicolumn{2}{c}{ Admission diagnosis } & \multicolumn{2}{c}{ Delayed diagnosis } \\
\hline Too late & 449 & $5 \cdot 5 \%$ & 394 & $7 \cdot 2 \%$ \\
Diagnosis uncertain & - & - & 898 & $16 \cdot 4 \%$ \\
Non-diagnostic ECG & - & - & 1052 & $19 \cdot 2 \%$ \\
Clinical contraindications & 167 & $2 \cdot 1 \%$ & 65 & $1 \cdot 2 \%$ \\
Prolonged resuscitation & 107 & $1 \cdot 3 \%$ & 50 & $0 \cdot 9 \%$ \\
Cerebrovascular disease & 86 & $1 \cdot 1 \%$ & 57 & $1 \cdot 0 \%$ \\
Risk of upper GI bleeding & 36 & $0 \cdot 4 \%$ & 16 & $0 \cdot 3 \%$ \\
Recent surgery & 20 & $0 \cdot 2 \%$ & 21 & $0 \cdot 4 \%$ \\
Hypertension & 4 & $0 \cdot 05 \%$ & 7 & $0 \cdot 1 \%$ \\
Chronic liver disease & 45 & $0 \cdot 5 \%$ & 24 & $0 \cdot 4 \%$ \\
Bleeding disorder & 29 & $0 \cdot 4 \%$ & 22 & $0 \cdot 4 \%$ \\
Proliferative retinopathy & 494 & $6 \cdot 1 \%$ & 262 & $4 \cdot 8 \%$ \\
Total & 206 & $2 \cdot 5 \%$ & 115 & $2 \cdot 1 \%$ \\
Other contraindications & 1149 & $14 \cdot 1 \%$ & 2721 & $49 \cdot 6 \%$ \\
Total contraindications & 8139 & & 5489 & \\
Number of infarctions & & & & \\
\hline
\end{tabular}

Percentages are stated as a proportion of the number of infarctions.

GI, gastrointestinal.
Patients with an admission diagnosis of infarction who were too late for thrombolytic treatment

Of the 8139 patients with an admission diagnosis of infarction $449(5.5 \%)$ were considered too late for treatment. The contraindication "too late" increased with age: 193 of 4039 $(4 \cdot 8 \%)$ younger than 65 years (the mean age) $v$ 272 of $4376(6 \cdot 2 \%)$ older than 65 , a difference of $1 \cdot 4 \%(99 \% \mathrm{CI}, 0 \cdot 1-2 \cdot 7)$. Women were more likely than men to receive too late as a contraindication: 158 of $2393(6.6 \%) v 291$ of $5746(5 \cdot 1 \%)$, a difference of $1.5 \%(99 \% \mathrm{CI}$, $0-3 \cdot 1)$.

Clinical contraindications in patients with an immediate diagnosis of infarction

There were 494 patients $(6 \cdot 1 \%)$ with an admission diagnosis of infarction who received a clinical contraindication to thrombolytic treatment related to risk of bleeding (table 3 ). Another 205 (2.5\%) had an alternative clinical contraindication recorded. These contraindications were free text entries used where the admitting doctor felt that there was a reason for not using thrombolytic treatment that was not included in the list of accepted contraindications. These included need for pacing (31 patients), cardiogenic shock (28), recent trauma (18), dissection not excluded (12), warfarin treatment (16), malignancy (7) unexplained anaemia (2), recent streptokinase treatment (4), elective angioplasty (2), and others or unclassified (85). Clinical contraindications were used less often for patients younger than the mean age of the group; 241 of $4039(6.0 \%) v 498$ of $4376(11.4 \%)$, a difference of $5 \cdot 4 \%(99 \% \mathrm{CI}, 3 \cdot 9-7 \cdot 0)$.

Clinical uncertainty and a non-diagnostic ECG in patients with a delayed diagnosis of infarction Clinical uncertainty (898 of 5489 patients, $16.4 \%$ ) and non-diagnostic ECG (1052 of 5489 patients, $19 \cdot 2 \%$ ) were the dominant contraindications for patients with a delayed diagnosis of infarction. Patients having the contraindication "clinical uncertainty" were those in whom there was clinical doubt as to the diagnosis as well as a non-diagnostic ECG, while "non-diagnostic ECG" was used where 
the history was strongly suggestive of infarction and the ECG did not show ST segments shifts consistent with the diagnosis.

Influence of previous myocardial infarction on use of thrombolytic treatment

There were 3320 patients with previous infarction among the 13628 of patients with this final diagnosis $(24 \cdot 2 \%)$. Patients with previous infarction were less likely to have a diagnosis of infarction recognised at admission to hospital, 1548 of $3320(46.6 \%) v 6591$ of 10308 $(63.9 \%)$, a difference of $17 \cdot 3 \%$ (99\% CI, 14.8-19.9). They received thrombolytic treatment less often, 2145 of $3320(64.6 \%) v 7614$ of $10308(73.9 \%)$, a difference of $9.3 \%(99 \%$ CI, 6.9-11·7). These differences were associated with a higher use of contraindications reflecting diagnostic and electrocardiographic uncertainty about the diagnosis. These contraindications were used for 713 of 3320 $(21.5 \%)$ patients with previous infarction $v$ 1237 of $10308(12.0 \%)$ without previous infarction, a difference of $9.5 \%(99 \% \mathrm{CI}$, $7 \cdot 5-11 \cdot 5)$.

\section{VARIATIONS IN USE OF THROMBOLYTIC} TREATMENT BETWEEN HOSPITALS

The range between hospitals of the use of thrombolytic treatment for an admission diagnosis of infarction was $67 \cdot 7 \%$ to $96 \cdot 7 \%$ and for a final diagnosis of infarction it was $49 \cdot 1 \%$ to $85 \cdot 4 \%$. To facilitate analysis, hospitals were ranked on the proportion of patients having thrombolytic treatment for a final diagnosis of definite infarction and divided into three groups: low use, average use, and high use. The average age of patients in each group was 66,65 , and 65 , respectively, and the percentage of males in each group was $69 \cdot 1 \%, 73 \cdot 1 \%$, and $68.9 \%$, respectively. The use of thrombolytic treatment for patients with a final diagnosis of infarction was: low use, $60.8 \%$; average use, $72 \cdot 4 \%$; high use, $80 \cdot 2 \%$.

The number of definite infarctions recognised at admission, as a proportion of the number having this final diagnosis, was: 1843 of $3586(51.4 \%)$ in the low use group; 3754 of $5949(63.1 \%)$ in the average use group; and 2542 of $4093(62 \cdot 1 \%)$ in the high use group.

The number of patients receiving thrombolytic treatment following an admission diagnosis of definite infarction was: 1504 of 1843 $(81.6 \%)$ in the low use group; 3226 of 3754

Table 4 Use of contraindications by three groups of hospitals with low, average, and high use of thrombolytic treatment

\begin{tabular}{|c|c|c|c|c|c|c|}
\hline & \multicolumn{3}{|c|}{$\begin{array}{l}\text { Admission diagnosis } \\
\text { definite infarction }\end{array}$} & \multicolumn{3}{|c|}{$\begin{array}{l}\text { Final diagnosis } \\
\text { definite infarction }\end{array}$} \\
\hline & Low use & Average & High & Low use & Average & High \\
\hline Too late & $\begin{array}{l}149 \\
8 \cdot 1 \%\end{array}$ & $\begin{array}{l}189 \\
5.0 \%\end{array}$ & $\begin{array}{l}111 \\
4 \cdot 4 \%\end{array}$ & $\begin{array}{l}277 \\
7 \cdot 7 \%\end{array}$ & $\begin{array}{l}346 \\
5 \cdot 8 \%\end{array}$ & $\begin{array}{l}220 \\
5 \cdot 4 \%\end{array}$ \\
\hline Clinical contraindications & $\begin{array}{l}190 \\
10 \cdot 3 \%\end{array}$ & $\begin{array}{l}339 \\
9 \cdot 0 \%\end{array}$ & $\begin{array}{l}171 \\
6 \cdot 7 \%\end{array}$ & $\begin{array}{l}319 \\
8 \cdot 8 \%\end{array}$ & $\begin{array}{l}491 \\
8 \cdot 3 \%\end{array}$ & $\begin{array}{l}267 \\
6 \cdot 5 \%\end{array}$ \\
\hline Clinical uncertainty & - & - & - & $\begin{array}{l}458 \\
12 \cdot 8 \%\end{array}$ & $\begin{array}{l}251 \\
4 \cdot 2 \%\end{array}$ & $\begin{array}{l}189 \\
4.6 \%\end{array}$ \\
\hline Non-diagnostic ECG & - & - & - & $\begin{array}{l}362 \\
10 \cdot 1 \%\end{array}$ & $\begin{array}{l}554 \\
9 \cdot 3 \%\end{array}$ & $\begin{array}{l}136 \\
3.3 \%\end{array}$ \\
\hline Total contraindications & $\begin{array}{l}339 \\
18.4 \%\end{array}$ & $\begin{array}{l}528 \\
14 \cdot 1 \%\end{array}$ & $\begin{array}{l}282 \\
11 \cdot 1 \%\end{array}$ & $\begin{array}{l}1416 \\
39 \cdot 5 \%\end{array}$ & $\begin{array}{l}1642 \\
27 \cdot 6 \%\end{array}$ & $\begin{array}{l}812 \\
19 \cdot 8 \%\end{array}$ \\
\hline Number of infarctions & 1843 & 3754 & 2542 & 3586 & 5949 & 4093 \\
\hline
\end{tabular}

(85.9\%) in the average use group; and 2261 of $2542(88.9 \%)$ in the high use group. The difference between low and average use was $4 \cdot 3 \%(99 \% \mathrm{CI}, 1 \cdot 6-7 \cdot 1)$, and between average and high use it was $3 \cdot 0 \%(99 \% \mathrm{CI}, 0 \cdot 8-5 \cdot 2)$. For patients who did not have a final diagnosis of infarction the use of thrombolytic treatment was similar: low use, 120 of $2358(5 \cdot 1 \%)$; average use, 228 of $4763(4.9 \%)$; high use, 225 of $3656(6 \cdot 1 \%)$.

Patients with previous infarction in the low use group were less likely to have further infarction recognised and treated with thrombolytic drugs than patients in the average and high use groups: low use, 341 of $986(39 \cdot 7 \%)$; average use, 714 of $1426(50.0 \%)$; high use, 443 of $908(48 \cdot 6 \%)$.

For patients with an admission diagnosis of definite infarction "too late" and "clinical contraindications" were used less frequently as use of thrombolytic treatment increased (table 4). For a final diagnosis of definite infarction a similar trend was observed for these contraindications and a more extreme trend in the use of the contraindications clinical uncertainty and non-diagnostic ECG was observed, these contraindications being used almost three times more frequently in the group of hospitals with the lowest use of thrombolytic treatment than the highest.

\section{Discussion}

Data were recorded between November 1992 and June 1995 from 39 district general hospitals with an average input of 349 patients (range 97-836) with a final diagnosis of myocardial infarction. These data come from hospitals with a wide geographical spread and might be considered typical of recent UK practice.

ELIGIBILITY FOR THROMBOLYTIC TREATMENT There were $59.7 \%$ patients with a final diagnosis of myocardial infarction who had this diagnosis made at admission on the basis of a suggestive history confirmed by cardiographic changes. This diagnosis carried a positive predictive value for confirmed myocardial infarction of $96.7 \%$. When these data were recalculated on the criteria used by French $^{12}$ (using patients with a final diagnosis of definite or probable infarction and excluding patients who were too late) $54.5 \%$ of patients were eligible compared with $53.3 \%$ in that study.

It is recognised that typical ECG changes of infarction may be transient or slow to evolve, ${ }^{13}$ so that a proportion of patients will only become eligible for thrombolytic treatment at some point after admission, emphasising the importance of frequent review of the cardiograph to ensure appropriate treatment. In this study 2177 of 13628 patients $(16 \%)$ developed qualifying ST segment changes or left bundle branch block after admission and received thrombolysis. This figure is likely to represent the majority of remaining eligible patients although this cannot be stated with certainty as the cardiographic appearances of 
patients not having thrombolytic treatment were not recorded in this study. Thus, $75.7 \%$ patients were eligible for treatment with a proviso that this may be lower than the true figure if any other patients who developed qualifying ST segment shifts after admission were not recognised. This figure lies within the range proposed by Ketley and Woods. ${ }^{8}$

\section{INELIGIBLE PATIENTS}

In this study 3312 of 13628 patients (24.3\%) with a final diagnosis of infarction did not have typical ECG changes (or did not have them recognised). This figure is lower than the $32.3 \%$ recorded by French from New Zealand ${ }^{12}$ and may indicate a lower threshold for the use of thrombolytic treatment for borderline cardiographic appearances in the UK. Of these patients, 591 received thrombolytic treatment.

The group of patients without typical ST segment changes represent a spectrum. This includes patients who have small infarctions unlikely to benefit from thrombolytic treatment, and in whom the risk:benefit ratio may be adverse; patients with extensive ST segment depression where severe three vessel disease is found postmortem and where evidence of benefit is uncertain despite being a high risk group; ${ }^{14}$ and patients with previous infarction who do not always present with typical changes but who have a high mortality and may benefit from thrombolytic treatment. ${ }^{14}$ It seems biologically implausible that the benefit of thrombolytic treatment should be entirely limited to patients having ST segment elevation on the ECG. Uncertainty concerning benefit for those having infarction with atypical cardiographic changes is partly because they are a heterogenous group in terms of risk and partly because, at least for patients with extensive ST segment depression, the available evidence neither confirms nor excludes the possibility of benefit. ${ }^{14}$ The overall picture is far from clear, and in some areas it is paradoxical. Although patients with previous infarction appear to benefit from treatment ${ }^{14}$ they frequently present with ST segment depression, a group presently thought not to show evidence of benefit. ${ }^{1415}$ Even patients admitted with suspected infarction who have minor cardiographic changes have significant early mortality. In ISIS-2 patients randomised to a placebo arm, not all of whom would have had infarction, and who had a cardiographic classification of other abnormality had a 35 day mortality of $5 \cdot 4-6 \cdot 3 \% .^{4}$

No trial has explicitly examined the effect of thrombolytic treatment for patients with definite infarction and atypical ECG changes. Lack of evidence of benefit is not good evidence of lack of benefit. The possibility remains that some patients with infarction and atypical ECG changes may benefit from thrombolytic treatment. In present UK practice it would appear that some patients from this uncertain group are presently receiving the benefit of the doubt. Doubt will remain until a definitive study in this group of patients is performed.
USE OF CONTRAINDICATIONS

The LATE study showed that significant benefit from treatment did not extend beyond 12 hours after onset of symptoms. ${ }^{16}$ Collaborators in this audit adopted local protocols; data on file suggests that in practice the time window accepted for use of thrombolytic treatment is greater than 12 hours in some hospitals. Older patients and women (who present at an older age) were more often too late for treatment. This may reflect the atypical nature of symptoms in the elderly, ${ }^{17}$ and in women, ${ }^{18}$ and the greater use of general practitioner contact by both groups as a means of admission to hospital.

The use of clinical contraindications in $6.1 \%$ of patients with an admission diagnosis of infarction is similar to recent published work from New Zealand $(6 \cdot 8 \%) .{ }^{12}$ The "other" clinical contraindications used in this study included a number of contraindications which appear overcautious or inappropriate, such as the need for pacing, or when there was cardiogenic shock. There was a trend to greater use of clinical and other contraindications by the hospitals who used the least thrombolytic treatment, which may reflect excessive caution. When patients had a delayed diagnosis the dominant reasons for not using thrombolytic treatment were clinical uncertainty or a non-diagnostic cardiograph. Both of these contraindications involve subjective judgment, with use determined by the clinical acumen of the clinician, or by the strictness of interpretation of the ECG criteria.

THE INFLUENCE OF PREVIOUS INFARCTION About one quarter of patients with a diagnosis of infarction have had previous infarction. They have a high mortality rate and may benefit from thrombolytic treatment. ${ }^{14}$ Previous infarction makes ECG recognition of further infarction more difficult. ${ }^{15}$ The lower use of thrombolytic treatment for patients with previous infarction found in this study supports this finding. Only $46.6 \%$ of patients with previous infarction had the diagnosis recognised at admission. As a result of this diagnostic uncertainty patients with previous infarction received thrombolytic treatment less often than first infarctions $(64.6 \% \quad v \quad 73.9 \%)$. Patients with previous infarction admitted to hospitals with a low use of thrombolytic treatment were also less likely to have previous infarction recognised and treated with thrombolytic drugs than patients admitted to the average or high use groups $(39.7 \%$ v $50.0 \%$ and $48.6 \%$ ). It is clear that patients with previous infarction are at a disadvantage. The frequency with which the diagnosis is missed at admission may represent a lack of clinical awareness, as in the low use group, but might also be improved by the use of rapid assay enzyme analysis.

DIFFERENCES IN PRACTICE BETWEEN HOSPITALS IN THE LOW, AVERAGE, AND HIGH USE GROUPS Increasing use of the contraindications "too late" and "clinical contraindications" accounted for the difference in the use of 
thrombolytic treatment for patients with an admission diagnosis of infarction (table 4). These differences are more marked for a final diagnosis of infarction. There was a threefold difference in the use of the contraindications "clinical uncertainty" and "non-diagnostic ECG" between the low and high use groups, which was the main but not only factor in the observed differences. It is probable that these differences are determined by local policy and attitudes to treatment, rather than intrinsic differences between groups.

Making an immediate diagnosis of infarction is the crucial first step in treating infarction with thrombolytic drugs. This diagnosis was made less often in the low use group than the other two groups (low use $51 \cdot 4 \%$, average use $63 \cdot 1 \%$, high use $62 \cdot 1 \%$ ), and subsequent use of thrombolytic treatment was less (low use $81.6 \%$, average use, $86.8 \%$, high use $88.9 \%$ ). The impact of these differences was substantial. For 100 patients with a final diagnosis of infarction in the low use group only 42 could expect treatment on the basis of an admission diagnosis of infarction, while in the average and high use groups 55 patients were treated. However, the frequency with which thrombolytic treatment was given for a diagnosis that was neither definite or probable infarction, $5 \%, 4.9 \%, 6 \cdot 1 \%$, for low, average, and high use groups, respectively, does not indicate that higher use of thrombolytic treatment was achieved at the expense of higher inappropriate use.

\section{CONCLUSIONS}

In this study, $75 \cdot 7 \%$ of patients with a final diagnosis of definite infarction were considered eligible for thrombolytic treatment on the basis of cardiographic findings either at admission or subsequently after further cardiographic evidence. Of patients with a final diagnosis of myocardial infarction, $71.6 \%$ had thrombolytic treatment of whom $67 \cdot 3 \%$ were eligible on the basis of cardiographic changes. A further $4 \cdot 3 \%$ without typical ECG changes received thrombolytic treatment although the role of therapy for this group is unclear.

In 39 hospitals the range of treatment with thrombolytic treatment for a final diagnosis of infarction was $49 \cdot 1 \%$ to $85.4 \%$. Some features of use in hospitals having a low use of thrombolytic treatment suggest that more patients with an immediate diagnosis of infarction should be recognised and that higher appropriate utilisation of thrombolytic treatment should be possible.

Significant numbers of patients with a final diagnosis of infarction do not have typical cardiographic changes; the role of thrombolytic treatment for this group is not clear.

Contributing hospitals-Northampton, Dr JS Birkhead (Data coordinator Jane O'Callaghan); Carlisle, Dr RH Robson; Redditch, Dr P Lowry; Reading (Royal Berks), Dr J Bell; Reading (Battle), Dr J Bell; York, Dr R Boyle; St Leonards-on- sea, Dr R Wray; Newcastle Upon Tyne, Dr D Reid; Brighton, Professor R Vincent; Merthyr Tydfil, Dr E Griffiths; Paisley, Dr IN Findlay; Torquay, Dr CM Carey; Swansea, Dr P Thomas; Derby, Dr MW Millar-Craig; Kettering, Dr G Baines; Telford, Dr ME Heber; Chertsey, Dr M Joy; Uxbridge, Dr G Sutton; London (Whittington), Dr D Patterson; Hull, Dr MS Norell; High Wycombe, Dr G Hendry; Rotherham, Dr PC Haste; Barnsley, Dr WE Rhoden; Stourbridge, Dr J Flint; Cottingham, Dr GC Kaye; Darlington, Dr J Murphy; Worcester, Dr D Tibbutt; Stafford, Dr JL Francis; Bristol, Professor J Vann Jones; Sutton in Ashfield, Dr J Rowley; Portsmouth (St Mary's), Dr J Watkins; Portsmouth (Queen Alexandra), Dr J Watkins; Pontefract, Dr RV Lewis; WestonSuper-Mare, Dr EJ Wakley; Aylesbury, Dr P Collins; Milton Keynes, Dr DJ Gwilt; Poole, Dr A McLeod; West Bromwich, Dr RA Ahmad; Banbury, Dr I Arnold.

Funding for this work was provided by the Department of Health through the Research Department of the Royal College of Physicians of London.

1 GISSI (Gruppo Italiano per lo Studio della Streptochinesi nell'Infarto miocardico). Effectivness of intravenous thrombolytic treatment in acute myocardial infarction. Lancet 1986;i:397-401.

2 ISAM (Intravenous Streptokinase in Acute myocardial Infarction) Study Group. A prospective study of intravenous streptokinase in acute myocardial infarction (ISAM): mortality, morbidity, and infarct size at 21 days. (ISAM): mortality, morbidity, and in

3 AIMS (APSAC Intervention Mortality Study) Trial study group. Effects of intravenous APSAC on mortality after acute myocardial infarction: preliminary report of a placebo-controlled clinical trial. Lancet 1988;i:545-9.

4 ISIS-2 (Second International Study of Infarct Survival) Collaborative Group. Randomised trial of intravenous streptokinase, oral aspirin, both, or neither among 17187 cases of suspected acute myocardial infarction: ISIS-2. Lancet 1988;ii:349-60.

5 ISIS-3: a randomised comparison of streptokinase $v$ tissue plasminogen activator $v$ anistreplase and of aspirin plus heparin $v$ aspirin alone among 41229 cases of suspected acute myocardial infarction. ISIS-3 (Third International Study of Infarct Survival) Collaborative Group. Lancet 1992;339:753-70.

6 ISIS-4: A randomised factorial trial assessing early oral captopril, oral mononitrate, and intravenous magnesium sulphate in 58050 patients with suspected acute myocardial phate in 58050 patients with suspected acute myocardial
infarction. ISIS-4 (Fourth International Study of Infarct infarction. ISIS-4 (Fourth International Study of Infarct

7 GISSI-2: a factorial randomised trial of alteplase versus steptokinase and heparin versus no heparin among 12490 patients with acute myocardial infarction. Lancet 1990; 336:65-71.

8 Ketley D, Woods KL. Impact of clinical trials on clinical practice: example of thrombolysis for acute myocardial infarction. Lancet 1993;342:891-4.

9 Birkhead JS on behalf of a Joint Audit Committee of the British Cardiac Society and the Cardiology Committee of the Royal College of Physicians of London. Time delays in provision of thrombolytic therapy in six district hospitals. provision of throm $1992305: 445-8$.

10 Rogers WJ, Bowlby LJ, Chandra NC, French WJ, Gore JM, Lambrew CT, et al. Treatment of myocardial infarction in the United States (1990 to 1993). Circulation tion in the United

11 Phillips BG, Yim JM, Brown EJ, Bittar N, Hoon TJ, Celestin C, et al. Pharmacologic profile of survivors of acute myocardial infarction at United States academic hospitals. Am Heart f 1996;131:872-7.

12 French JK, Williams BF, Hart HH, Wyatt S, Poole JE, Ingram C, et al. Prospective evaluation of eligibility for thrombolytic therapy in acute myocardial infarction. $B M \mathcal{F} 1996 ; 312: 1637-41$.

13 Adams J, Trent $R$, Rawles J, on behalf of the GREAT group. Earliest electrocardiographic evidence of myocardial infarction: implications for thrombolytic treatment. $B M \mathcal{F}$ 1993;307:409-12.

14 Fibrinolytic Therapy Trialists' (FTT) Collaborative Group. Indications for fibrinolytic therapy in suspected acute myocardial infarction: collaborative overview of early mortality and major morbidity results from all randomised trials of more than 1000 patients. Lancet 1994; 343:311-22.

15 Hai Shiang Lee, Cross SJ, Rawles JM, Jennings KP. Patients with suspected myocardial infarction who prePatients with suspected myocardial infarction who

16 LATE Study Group. Late assessment of thrombolytic efficacy (LATE) study with alteplase 6-24 hours after onset cacy (LATE) study with alteplase 6-24 hours after onset

17 Aronow WS. Prevalence of presenting symptoms of recognised acute myocardial infarction and unrecognised healed myocardial infarction in elderly patients. $\mathrm{Am} \mathfrak{J}$ healed myocardial in

18 Karlson BW, Herlitz J, Hartford M. Prognosis in myocardial infarction in relation to gender. Am Heart $\mathcal{F} 1994$; 128:477-83. 